\section{Improved access to care or lowered standard of care?}

\author{
J. Blood'
}

IN BRIEF
Describes the debate regarding the use of
dental therapists.
- Explores moral obligations, conflicts of
interest and long-term consequences
that must be considered.
- Highlights the need to protect and
support all parties involved in the
decision of whether to encourage the
advancement of dental therapy.

\begin{abstract}
Health disparities abound in every profession, dentistry included. The most recent attempt to solve dental disparities that has been brought to light is the idea of training dental therapists in order to expand the dental workforce. While dental therapists have been around since the 1970s, only recently has the issue of allowing them to practice in the continental US been so forcefully raised and questioned. With the new healthcare act that will provide access to millions more starting in 2014, these disparities are getting much harder to ignore. We as healthcare professionals have a duty to strive to improve access to quality care and we will not know what quality of care is being provided until these therapists prove (or disprove) themselves. However, we must remember that all three populations - patients, therapists and dentists - must be heard, respected and protected as we navigate this new road to collaboration.
\end{abstract}

\section{INTRODUCTION}

Dentistry suffers health disparities like any healthcare profession but the suggestion of training dental therapists in order to expand the dental workforce may solve such problems. Dental therapists have been around since the 1970s, but only now has the issue of allowing them to practise in the continental US been so forcefully raised and questioned. With the new healthcare act that will provide access to millions more starting in 2014, these disparities are getting much harder to ignore. This paper will explore the pros and cons of allowing mid-level providers such as dental therapists to perform irreversible procedures while discussing the ethical implications involved in the decision to support the shift toward less-educated, less-expensive care providers.

\section{IMPROVING ACCESS TO CARE?}

Currently, in the United States, Alaska and Minnesota allow dental therapists to perform basic dental procedures under supervision of a licensed dentist. These

'Loma Linda University, Moreno Valley, 92557 United States

Correspondence to: Jamie Blood

Email:jherra@llu.edu

Accepted 10 July 2013

DOI: 10.1038/sj.bdj.2013.949

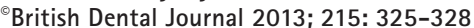

therapists are trained in programmes that were initially instituted by several foundations, namely the Rasmuson Foundation and the W. K. Kellogg Foundation. The American Dental Association (ADA) has questioned the wisdom of these programmes, claiming that there is no consensus on the 'specific prerequisites, scope or duration of educational programme, or other critical attributes needed to define any academic model' and the procedures that therapists are allowed to perform can differ drastically depending on the location and the practitioner that they are working under. ${ }^{1}$ According to the dental state board regulations, therapists are to refer patients to qualified professionals if the patient has needs that exceed their scope of practice; however, the regulations go on to say that an advanced practice therapist cannot perform certain services or procedures 'except as authorised by the collaborating dentist.' While dental therapy may be an 'innovative and controversial health position intended to fill socioeconomic and geographic gaps in dental care, ${ }^{3}$ it may be too easily abused, resulting in harm to the patients.

The (ADA) argues that mid-level providers such as dental therapists cannot have the training and education necessary to perform irreversible surgical procedures and that their emphasis in training on the technical side of dentistry may limit their ability to identify patients' other medical problems. ${ }^{3}$ The ADA issued a statement in support of the work that was put into finding ways to improve oral health and access to care but declared that they did not believe a 'non-dentist should perform surgical/irreversible procedures,' an innovation that they believe would compromise the very system that we are all seeking to extend. ${ }^{1}$ Their statement pointed out that it was the "lawmakers, charitable organisations and other stakeholders - some of them with very little experience in or understanding of oral healthcare' that were pushing for alternative means of providing care such as by training dental therapists. ${ }^{1}$ The California Academy of General Dentistry (CAGD) argued that 'high school graduates with a few years of training could end up performing delicate procedures with permanent consequences. ${ }^{3}$

Supporters of mid-level providers argue that therapists are properly and adequately trained. The Minnesota curriculum is quite rigorous - this full-time, 28-month Masters of Science programme "blends a solid dental clinical education with the biological, behavioural, and social sciences, and the liberal arts. ${ }^{4}$ The programme is affiliated with an accredited dental school and therapy students take courses with dental and dental hygiene students, working together with them on the clinic floor. The curriculum includes an 'emphasis on 
leadership, education and public health' and a commitment to "community service and to intellectual development and critical thinking. ${ }^{5}$ One clinic that employs dental therapist graduates reported that they are 'seeing the same quality and the same or better productivity, while paying 30\% less an hour to do the same restorative procedures.' $^{\prime}$

Other proponents of dental therapy argue that therapists would help to close gaps in care, thereby reducing the number of costly emergency room visits for dental problems. According to Shelly Gehshan, director of the Children's Dental Campaign, there were approximately 830,000 emergency room visits in 2009 due to preventable dental problems. ${ }^{3}$ She argued that more qualified people are needed in order to expand the reach of the dental system to those who either don't have insurance, live in areas with an insufficient number of dentists or are not able to find doctors who accept their coverage. Gehshan claimed that any concerns about competition are unwarranted and that therapists would not 'threaten dentists' identity, their control over the profession or their incomes. ${ }^{3}$

\section{QUALITY OF CARE}

Is this inability of some dentists and dental therapists to see 'eye-to-eye' simply competitive fear on the dentists' part or are dentists the best experts to determine whether therapists are competent and can provide quality, comprehensive care to their patients? Bill Calnon, the ADA president, argued that dentists are not concerned about competition but safety. He stated, 'this is about dentists doing what they feel is the absolute best for the American public... and doing it in a way that maintains the highest level of quality care possible. ${ }^{3}$ As Dr Howard Gamble, president of the Academy of General Dentistry (AGD) suggested, 'they say they're only going to do simple procedures but, often you can't say whether it was simple or not until after you're finished and you decide it was simple. ${ }^{4}$ Dr Gamble discussed how most recent doctorate graduates do not jump straight into their own practice but continue to work under more experienced dentists for several years. ${ }^{4}$

How do we accurately and fairly judge the quality of care that these therapists are providing? We cannot simply trust the patients to tell us how the therapists are doing; patients are often unaware of what has been done in their mouth and base their opinions solely on the practitioner's interactive skills. Of course, 'bedside manner' is incredibly important and a vital part of maintaining one's patient family but just because a person has an outstanding personality does not mean that they have the right or ability to perform irreversible procedures.

We cannot hold a higher standard for these therapists and apply this logic only to them. We must judge the work of the licensed dentist with the same critical eye in order to better understand the impact of therapists. However, it is important to consider what the consequences may be if any of these concerns about therapists are valid. While they will certainly improve access to care initially, if they are not providing quality care, the access may actually be further limited due to the need for patients to receive care by a specialist - it is often the case that fixing poor dental work is more difficult and requires more expertise than working on a virgin tooth does. For patients who do not have access to, or finances for a specialist, the rate of tooth loss may be increased leading to a new set of problems including need for further care and compromised long-term oral health and prognosis. Again, the title behind one's name does not automatically determine the standard of care being provided - all practitioners must take a personal oath to provide exceptional care, whether by treating the patient themselves or by referring them to a more qualified provider.

In one of the largest studies conducted on the standard of care provided by dental therapists, the W. K. Kellogg Foundation found that dental therapists offer treatment that is "technically competent, safe and effective, especially for children.7 Can work that focuses only on the technical aspect of dentistry - and on providing short-term relief of symptoms rather than addressing the root of the problem - be considered competent and effective? The lead author of the study, Dr Nash, went on to say that the study should 'put to rest once and for all' the controversy over whether therapists provide safe and effective basic dental care. ${ }^{7}$ This shortsighted interpretation raises questions as to the degree of bias incorporated into the author's conclusions. The ADA responded to the Kellogg study, saying that it failed to 'rise to the level of a systematic literature review, nor does it adequately address some of the key indicators of whether and to what extent the use of therapists improves public oral health. ${ }^{7}$

The opinions of dentists are as varied as those of the organisations that argue about the use of therapists. One dentist in St Paul, Minnesota, who employs dental therapists believes that having a mid-level provider in his office enables him to practise at the 'top of [his] licence' - he enjoys the opportunity to use his 'diagnostics and brain skills rather than the hand skills. ${ }^{6}$ Friedman stated that dental therapists enable dentists to "practise at a higher level of proficiency and efficiency' by providing quality basic care and through their wide acceptance by the public. ${ }^{8}$ Other dentists enjoy the hands-on aspect of their profession and don't want to be reduced to a 'brain', believing that a dentist who practises the hands-on part will be equipped to provide more thorough, accurate diagnoses. We must question the wisdom of limiting dentists' roles to diagnostician while allowing them to lose their edge clinically. If a dentist wants to work with competent therapists to serve those in need but is not clinically adept, it may be more difficult for him or her to provide the diagnostic standard of care that would allow the therapist to provide ethically and functionally adequate clinical care.

\section{THE ROLE OF THE DENTIST}

Lopez et al. explored the attitudes and perceptions of dental school faculty members in regards to their roles in training new dental therapist students. ${ }^{9}$ The study found that faculty members believed that dentists have a personal responsibility to care for the underserved but that they did not agree that therapists are part of the solution to improve access. The authors also found that there was an overall consensus that the faculty members have a commitment and responsibility to educate future dental therapists regardless of their personal position. ${ }^{9}$

Are we glossing over important ethical concerns in regards to this new profession? Perhaps we need to reconsider whether we should be asking dentists to support a 
profession that they are not comfortable supporting and do not necessarily think will be beneficial to patients. We must explore the ways that this could affect the dentist's perception of themselves and their profession. If we ask them to support the training of dental therapists, we cannot ignore the fact that their biases can affect the quality of learning that their students receive. If both parties come to resent one another, the collaborative relationships that will be vital to the future of dental therapy will undoubtedly be hindered.

Should we be worried about the populations that dental therapists are learning on? Minnesota requires therapists to work in low-income or dental shortage areas ${ }^{4}$ while Alaska is known to only allow them to practise on tribal rural areas. As therapists gain experience, Minnesota law permits them to work without onsite supervision of a licenced dentist in 'nursing homes, Head Start clinics, homeless shelters or emergency rooms. ${ }^{6}$ Perhaps therapists are not limited to these populations to help close the gap in care but for less praiseworthy reasons. It has been argued that therapists provide safe and competent care but we must ensure that we are not judging them by a lower standard because the population they treat consists mainly of children, elderly, poor and uneducated populations with limited options and therefore limited ability to know better or say no.

\section{FINANCIAL BURDEN}

If we do not support the use of dental therapists, we must explore other alternatives. The simplest, financially and ethically preferable way may be working with the practitioners we already have to encourage and enable an interest in serving other populations. Giving tax credits to dentists who work in underserved or rural populations could help. ${ }^{4}$ Dr Michael Flynn points out that the reimbursement rates he receives for seeing low-income patients is 'not sustainable' in his practice. ${ }^{6}$ Dr Flynn works in a small city as the only dentist for miles and with a reimbursement from Medicaid of 30 cents on the dollar (and with no dental coverage for seniors), he has been forced to lay off workers and limit the number of poor and uninsured patients he can see. ${ }^{6}$ Improved incentives may increase the number of participating dentists and better disperse the burden of care that falls 'disproportionately on a few members of the profession. ${ }^{10}$

Perhaps we should invest in current dental students to enhance their interest in serving the community, increasing the chances that they will work in underserved areas following graduation. Graham explored the idea of recruiting minority students or those with previous volunteer experience and exposing them to learning experiences in the community as a means to increase their willingness to continue serving in these areas. ${ }^{11}$ Formicola et al. ${ }^{10}$ also suggested encouraging students to spend more time in community sites to better equip them to treat diverse, lowincome patients; the authors found that participating dental schools successfully 'developed networks of community clinics [and] established courses in cultural competency and public health. ${ }^{12}$

Financial support for dental students may also enable new graduates to devote more time and resources to the underserved. DePaola found that dental education is the "most costly professional degree education within the entire university portfolio and dental student accumulated debt is increasing each year well beyond national inflation estimates. ${ }^{13}$ With the crushing debt many dentists work under, is it any wonder that some are hesitant to accept less for their work? Although it should not be a priority in our discussions, we cannot underestimate the negative impact that the use of therapists may have on the population of practising dentists. Lazar et al. found that the use of therapists in general practices did not result in a significant reduction in costs but did have a negative effect on most dentists' gross income, hours of work, and net income. ${ }^{14}$

Alternatively, we could invest the funds used to train dental therapists directly into the community. If we focus on teaching people how to improve their oral health with regular hygiene and diet modifications, we may be able to help curb dental disease and therefore, the 'growing gap of dental care. ${ }^{4}$ According to public health officials, the vast majority of dental disease is preventable, yet nearly 17 million children do not see a dentist every year. ${ }^{6}$ Why is this? Medicaid in Minnesota provides dental coverage to nearly 400,000 lowincome and disabled children, only $42 \%$ of which actually receive dental care each year. According to the same article, 60\% of children with private insurance get dental care. ${ }^{6}$ We must decide whether this discrepancy is largely due to the limited number of dentists who will see Medicaid patients or whether the motivation of and collaboration with parents is a larger issue than we currently think it is.

The ADA contends that America's dental crisis will only be reversed through more structural changes that focus on prevention such as 'community water fluoridation; first dental visits by age one; oral health education, assessments and sealant programmes in schools; better integration with the medical community; and realistic funding of care for those in greatest need.7 Wallace et al. explored the perceptions of dentists and low-income patients in regard to why the current model of care does not work. The authors found that 'patients' concerns about the cost of dentistry, dentists' reluctance to treat this population, and the cultural incompatibility of most private practices to the needs of lowincome communities' reinforce the need for other responses to adequately address the multiple dimensions of access. ${ }^{15}$ Not only do our communities need education but our political leaders, fellow health professionals and dentists themselves must also realise the need to work together to improve care; we must find a way to make oral healthcare a public priority ${ }^{16}$ by closing the "distance that separates the health professions' perspective from much of mainstream American thinking., ${ }^{17}$

\section{CONCLUSIONS}

Health professionals have a moral obligation to provide care to the underserved and vulnerable. ${ }^{18}$ However, it is not easy to determine how to live up to that obligation. Should we respect autonomy above all else, allowing patients to make their own decisions in regards to what level of provider they want to see? Can we call it true autonomy for either patient or provider if therapists are forced to work in low-income areas and low-income patients are only offered the choice of 1) no treatment or 2) possibly inferior treatment? Are we doing good by improving access to care or are we causing harm by allowing less-educated providers to practise on the unsuspecting and possibly encouraging the 
more educated to seek a different career? Are we being unjust in assuming that dentists should embrace this new provider at whatever cost to their own well-being (and possibly the well-being of patients in the long term)?

If we continue to ignore the huge amount of student loans that dentists shoulder and expect them to bear the brunt of the financial burden of caring for the underserved, we run the risk of bankruptcy, burnout, resentment and a lack of interest in becoming a part of the profession, thereby lowering the standard of care provided by dentists as well as reducing the number of practising dentists, all of which would effectively exacerbate the lack of access to care. Whether or not dental therapy is effective, dentists and dental students need more support (financial and otherwise) to engage their interest and provide the ability for them to care for those who need it most. We have a duty to strive to improve access to quality care and we will not know what quality of care is being provided until these therapists prove (or disprove) themselves. However, we must remember that all three populations - patients, therapists and dentists - must be heard, respected and protected as we navigate this new road to collaboration.

1. Fox K. ADA responds to AAPHD educational plan for two-year dental therapist programme. ADA News, 2011. Online article available at http://www.ada.org/ news/5940.aspx (accessed July 2013).

2. Minnesota Board of Dentistry. Advanced dental therapist scope of practice. Minneapolis: Minnesota Board of Dentistry, 2009. Online scope of practice available at http://www.dentalboard.state.mn.us/ Portals/3/Licensing/Dental\%20Therapist/ADTSCOPE. pdf (accessed July 2013).

3. Gorman A. Traditional dentistry wary of dental therapists. LA: Los Angeles Times, 2012. Online article available at http://articles.latimes.com/2012/jun/03/ local/la-me-dental-battle-20120603 (accessed July 2013).

4. ABC News. Dental therapists fill a void but dentists question their training. ABC News, 2012.

5. University of Minnesota. Master of dental therapy program: a one-of-a-kind program. Online information available at http://www.dentistry.umn.edu/ programs-admissions/advanced-programs/dentaltherapy/index.htm (accessed July 2013).

6. Crosby J. Dental therapists bridge gap. Star Tribune 2012. Online article available at http://www. startribune.com/business/162430866.html?refer $=y$ (accessed July 2013).

7. Bowser B A. Dental therapists 'safe' pulling
American teeth, study suggests. PBS Newshour 2012. Online article available at http://www.pbs.org/ newshour/rundown/2012/04/relief-ahead-for-usdental-crisis-report-finds-therapists-effective.html (accessed July 2013).

8. Friedman $J \mathrm{~W}$. The international dental therapist: history and current status. J Calif Dent Assoc 2011; 39: 23-29.

9. Lopez N, Blue C M, Self K D. Dental school faculty perceptions of and attitudes toward the new dental therapy model. J Dental Educ 2012; 76: 383-394.

10. Formicola A, Bailit H, D'Abreu K et al. The Dental Pipeline Program's impact on access disparities and student diversity. J Am Dent Assoc 2009; 140: 346-353.

11. Graham B S. Educating dental students about oral health care access disparities. J Dent Educ 2006: 70: 1208-1211.

12. Smith D H. Band-aid solutions to problems of access: their origins and limits. J Dent Educ 2006; 70: $1170-1173$.

13. DePaola D P. Reforming dental health professions education: a white paper. J Dent Educ 2004; 68: 1139-1150.

14. Lazar V F, Guay A H, Heffley D R, Bailit H L. Dental therapists in general dental practices: an economic evaluation. J Dent Educ 2012; 76: 1082-1091.

15. Wallace B B, Macentee M I. Access to dental care for low-income adults: perceptions of affordability, availability and acceptability. J Community Health 2012; 37: 32-39.

16. Ozar D T. Basic oral health needs: a public priority. $J$ Dent Educ 2006; 70: 1159-1165.

17. Ozar D T. Ethics, access, and care. J Dent Educ 2006; 70: 1139-1145.

18. Pelligrino E D. The medical profession as a moral community. Bull N Y Acad Med 1990; 66: 221-232. 